\title{
What Fisher knew about his relation, we sometimes forget ${ }^{\text {ts }}$
}

\author{
Neil Arnwine, Taner M. Yigit* \\ Department of Economics, Bilkent University, Bilkent, Ankara 06800, Turkey
}

\section{A R T I C L E I N F O}

Article history:

Received 19 May 2007

Received in revised form 30 July 2008

Accepted 7 August 2008

Available online 13 August 2008

\section{Keywords:}

Fisher relation

Interest rate

Consumption growth

JEL classification:

E43

\begin{abstract}
A B S T R A C T
Expected consumption growth increases the real interest rate as one tries to smooth consumption over time. We demonstrate that placing it in the Fisher relation 1) is consistent with the Euler equation governing the purchase of nominal bonds, 2) explains observed procyclicality of the real interest rate, 3 ) is supported empirically, and 4) provides an alternative method for estimating the consumer's degree of relative risk aversion.
\end{abstract}

(c) 2008 Elsevier B.V. All rights reserved.

\section{Introduction}

The Fisher relation simply states that the nominal interest rate equals the sum of the consumer's real rate of time preference and the expected inflation rate. Recent empirical studies (Crowder and Hoffman, 1996; Caporale and Pittis, 2004; Sun and Phillips, 2004; Phillips, 2005; Christopoulos and Leon-Ledesma, 2007; Westerlund, 2008) have addressed problems around the estimation of this relation, such as the existence of procyclical fluctuations in the real interest rate and the coefficient of inflation not being equal to 1 . While they focus solely on finding methodological solutions for the empirical failures of this relation, we suggest that theory can lend a hand. To be more specific, we use Fisher's argument that the time shape of income is a determinative factor of the real interest rate:

"The fact that a person's income ${ }^{1}$ is increasing tends to make his preference for present over future income high, as compared with what it would be if his income were flowing uniformly or at a slackening rate; for an increasing income means that the present income is relatively scarce and future income relatively abundant (Fisher, 1930, p. 73-74)."

To our knowledge, no previous empirical study has included the income trend found in Fisher's quote. The few studies that did include

\footnotetext{
is We would like to thank E. Basci, R. Gurkaynak, K. Hasker, I. Pastine, R. Rasche, S. Sayek and the anonymous referee for their comments. All remaining errors are our own.

* Corresponding author. Tel.: +90 312290 1643; fax: +90 3122665140.

E-mail address: tyigit@bilkent.edu.tr (T.M. Yigit).

1 By 'income' Fisher meant what we now refer to as 'consumption' (Fisher, 1930, I.I.61)
}

income (Levi and Makin, 1978; VanderHoff, 1984; Dotsey et al., 2003) view it as one of many factors defining general equilibrium market dynamics rather than justifying it as consumption smoothing. With the introduction of Lucas (1978) one can now formalize Fisher's statement with a time-dynamic optimization of the consumer's problem. In this study, we do just that and derive an augmented Fisher relation from the standard representative agent's Euler equation governing the demand for bonds that differs from the standard Fisher relation by the inclusion of an expected consumption growth term. We also demonstrate that this inclusion i) explains the observed procyclical fluctuations in the real interest rate, ii) is empirically significant, and iii) provides an alternative way to estimate the consumer's degree of relative risk aversion.

The paper is organized as follows: Section 2 elaborates on why and how we should add the consumption growth rate into the Fisher relation, Section 3 empirically examines the implications and interprets the results, and Section 4 concludes.

\section{Model}

Fisher's quote above is consistent with the analysis of the consumer's Euler equation for bond purchases:

$\frac{u_{c}(c)}{p}=\beta(1+\tilde{i}) E\left[\frac{u_{c}\left(c^{\prime}\right)}{p^{\prime}}\right]$

Here a prime denotes variables measured at time $t+1$, a tilde distinguishes the interest rate in levels from the log of one plus the interest rate used in some of the equations below and $E$ is the expectations operator at time $t$. The optimizing consumer equates the marginal utility of current consumption with the discounted expected 
future utility of consumption in the next period. Assuming a constant degree of relative risk aversion utility function,

$u(c)= \begin{cases}\frac{1}{1-\gamma} c^{1-\gamma} & \gamma \neq 1 \\ \ln c & \gamma=1\end{cases}$

Eq. (1) becomes

$$
(1+\tilde{i})^{-1}=\beta E_{t}\left[\frac{p}{p^{\prime}} \cdot\left(\frac{c}{c^{\prime}}\right)^{\gamma}\right]
$$

where $\gamma$ represents the consumer's degree of relative risk aversion. Expanding the expectation term we obtain

$$
(1+\tilde{i})^{-1}=\beta\left\{E_{t}\left(\frac{p}{p^{\prime}}\right) E_{t}\left(\frac{c}{c^{\prime}}\right)^{\gamma}+\operatorname{cov}\left[\frac{p}{p^{\prime}},\left(\frac{c}{c^{\prime}}\right)^{\gamma}\right]\right\}
$$

To simplify this expression we define the following terms

$\alpha=\ln \beta^{-1}, i=\ln (1+\tilde{i}), \pi^{\mathrm{e}}=-\ln E\left(\frac{p}{p^{\prime}}\right), g^{\mathrm{e}}=-\ln E\left(\frac{c}{c^{\prime}}\right)$

where $\alpha$ represents the consumer's rate of time preference, $i$ represents the nominal interest rate, $\pi^{\mathrm{e}}$ is the expected inflation rate, and $g^{\mathrm{e}}$ represents the expected consumption growth rate. ${ }^{2}$

Assuming that the covariance term in Eq. (4) is negligible, as expected in a low inflation risk economy (Sarte, 1998), we obtain our augmented Fisher equation by taking the natural log of both sides of Eq. (4) and substituting in the terms from Eq. (5)

$i=\alpha+\pi^{\mathrm{e}}+\gamma g^{\mathrm{e}}$

The nominal interest rate must compensate the consumer for the rate of time preference, the loss in purchasing power due to inflation, and the utility cost of expected consumption fluctuations. Since the coefficient on the consumption growth rate is the consumer's degree of relative risk aversion, Eq. (6) also provides us with an alternative way to estimate this important parameter.

\section{Data and estimation}

In testing the implications of our model, we use US quarterly data for 3-month Treasury constant-maturity bonds (Board of Governors), seasonally-adjusted real personal consumption expenditures (Bureau of Economic Analysis), and the consumer price index for urban consumers (Department of Labor) for the sample period of 1960Q4 to 2005Q4. Inflation and consumption growth expectations are proxied for by the actual 3-month growth rates of CPI and consumption data, respectively. To avoid artificial moving average problems, we select non-overlapping data points for (3-month) inflation and consumption growth, also dividing the T-Bill rates by four. Finally, since the Treasury rate reflects the yield to be collected one quarter after purchase, we align next quarter's inflation and consumption growth rates with the current quarter's interest rate (Sun and Phillips, 2004).

The standard cointegration techniques by Crowder and Hoffman (1996), Ng and Perron (1997), Dotsey et al. (2003), Caporale and Pittis (2004), and Sun and Phillips (2004) do not fit the purposes of our study since the consumption growth component is found to be stationary, ${ }^{3}$ and

\footnotetext{
2 The proper inflation measure is the 'inverse of the expected rate of decrease in purchasing power due to inflation' rather than the 'rate of inflation' itself. According to Jensen's inequality these are not the same in the presence of risk. The same also applies to the consumption growth rate. In this study we proxy for the measure of inflation and consumption expectations by a single point, namely the actual inflation or growth, so there is no difference between $-\ln E\left(p / p^{\prime}\right)$ and $\ln E\left(p^{\prime} / p\right)$ or $-\ln E\left(c / c^{\prime}\right)$ and $\ln E\left(c^{\prime} / c\right)$.

3 ADF tests, using the modified Akaike information criteria for lag selection, find that the T-Bill and inflation rates have a unit root, while rejecting the non-stationarity of consumption growth; the corresponding test statistics are $-1.87,-2.38$, and -5.92 , respectively.
}

Table 1

Reduced form and structural parameters from the joint test of the long- and short-run Fisher relation

\begin{tabular}{lccccc}
\hline & OLS (reduced) & IV (reduced) & & OLS (structural) & IV (structural) \\
\hline$\psi_{0}$ & $-0.04(0.06)$ & $-0.08(0.06)$ & $\rho_{0}$ & -0.37 & -0.82 \\
$\psi_{4}\left(\pi_{t-1}\right)$ & $0.14^{* * *}(0.03)$ & $0.14^{* * *}(0.03)$ & $\rho_{1}$ & $1.23^{\dagger}$ & $1.46^{\dagger}$ \\
$\psi_{5}\left(g_{t-1}\right)$ & $0.06^{*}(0.03)$ & $0.07^{*}(0.04)$ & $\rho_{2}$ & $0.51^{*}$ & $0.77^{*}$ \\
$\psi_{6}\left(i_{t-1}\right)$ & $-0.11^{* * *}(0.03)$ & $-0.09^{* * *}(0.03)$ & & \\
$\psi_{1,0}\left(\Delta \pi_{t}\right)$ & $0.10(0.03)$ & $0.11^{* * *}(0.04)$ & & \\
$\psi_{1,1}\left(\Delta \pi_{t-1}\right)$ & $0.07^{* * *}(0.03)$ & $0.07(0.04)$ & & \\
$\psi_{1,2}\left(\Delta \pi_{t-2}\right)$ & & $0.004(0.03)$ & & \\
$\psi_{2,0}\left(\Delta g_{t}\right)$ & $-0.01(0.02)$ & $-0.01(0.02)$ & & \\
$\psi_{2,1}\left(\Delta g_{t-1}\right)$ & $-0.06^{* * *}(0.02)$ & $-0.09^{* * *}(0.03)$ & & \\
$\psi_{2,2}\left(\Delta g_{t-2}\right)$ & & $-0.02(0.01)$ & & \\
$\psi_{3,1}\left(\Delta i_{t-1}\right)$ & $-0.03(0.07)$ & $-0.12(0.08)$ & & \\
$\psi_{3,2}\left(\Delta i_{t-2}\right)$ & & $-0.09(0.09)$ & & \\
$\bar{R}^{2}$ & 0.27 & 0.26 & & \\
Prob. Of J stat & & 0.99 & & \\
DW & 2.11 & 1.96 & & \\
\hline
\end{tabular}

Notes: Standard errors are reported in the parentheses. ${ }^{* * *}$ Indicates $99 \%$ significance while ${ }^{* *}\left({ }^{*}\right)$ indicates $95 \%$ (90\%). The structural parameters are estimated using the reduced form estimates, and their significance levels are tested using Wald $\left(\psi_{6}+\psi_{4}=0\right)$ and $t$-tests $\left(\psi_{5}=0, \psi_{0}=0\right)$. 'Indicates failure to reject the null of $\rho_{1}=1$.

is used to explain the short run fluctuations around the long-run Fisher relation. We follow Mehra (1993) who uses an error correction method to tackle a similar problem for the joint estimation of the long- and shortrun money demand function. While our long run Fisher equation is

$i_{t}=\rho_{0}+\rho_{1} \pi_{t}+\rho_{2} g_{t}+u_{t}$

its short run adjustment process incorporates the dynamic error correction changes:

$\Delta i_{t}=\theta_{0}+\sum_{s=0}^{n 1} \theta_{1, s} \Delta \pi_{t-s}+\sum_{s=0}^{n 2} \theta_{2, s} \Delta g_{t-s}+\theta_{3} u_{t-1}+\varepsilon_{t}$

Estimating both equations simultaneously in a reduced form equation yields:

$$
\begin{aligned}
\Delta i_{t}= & \psi_{0}+\sum_{s=0}^{n 1} \psi_{1, s} \Delta \pi_{t-s}+\sum_{s=0}^{n 2} \psi_{2, s} \Delta g_{t-s}+\sum_{s=1}^{n 3} \psi_{3, s} \Delta i_{t-s}-\psi_{4} \pi_{t-1}-\psi_{5} g_{t-1} \\
& +\psi_{6} i_{t-1}+\varepsilon_{t}
\end{aligned}
$$

which provides us with consistent estimates of the model's structural parameters: $\theta_{3}=\psi_{6}, \rho_{0} \cong-\psi_{0} / \psi_{6}$ (since $\left.\psi_{0}=\theta_{0}-\theta_{3} \rho_{0}\right), \rho_{1}=-\psi_{4} / \psi_{6}$ and $\rho_{2}=-\psi_{5} / \psi_{6}$. Due to possible endogeneity resulting from proxying for expectations, we estimate the model with both OLS and IV methodologies. ${ }^{4}$ The results are displayed in Table 1.

The first two numeric columns of Table 1 present the reduced form estimates while the last two display the structural parameters of Eq. (7), which are derived from the reduced form estimates. While we use standard $t$-statistics to calculate the significance levels of reduced form coefficients, we use a combination of Wald and $t$-statistics to test for null hypotheses of the long-run Fisher relation, namely $\rho_{1}=1\left(\psi_{6}+\right.$ $\left.\psi_{4}=0\right)$ and $\rho_{0}, \rho_{2}=0\left(\psi_{5}=0, \psi_{0}=0\right)$. First, we find that the long run inflation coefficient is not significantly different than one, as expected. Second, the time preference rate is insignificantly different than zero, which is consistent with the risk-free bond rate puzzle identified by Weil (1989). Third, the findings support our theory that consumption

\footnotetext{
${ }^{4}$ In OLS, $n 1, n 2$ and $n 3$ are all chosen as 1 while they are 2 in the IV estimation. They are determined by using the Schwartz information criterion. The instruments used in the IV model are 2 non-coincident lagged levels of T-Bill rate, inflation and consumption growth with 2 coincident lagged differences in interest rate and 4 lagged differences of inflation and consumption growth. Using lagged variables as instruments implies that the expectations are formulated with an OLS type estimation. Hence, it is as if we are replacing the actual inflation (and consumption growth) data with the market expectations formed by using past inflation data.
} 
growth is an important element in the Fisher relation. While the long run consumption growth parameter $\left(\rho_{2}\right)$ is only marginally significant, the short run fluctuation of consumption growth $\left(\psi_{2,1}\right)$ is a very significant determinant of interest rate fluctuations. This result is quite expected. While consumption growth expectation is variable in the short run, in the long run it is constant and thus difficult to distinguish from the consumer's constant pure rate of time preference. However, the strong significance of the dynamic error correction estimates $\left(\psi_{2,1}\right)$ show that consumption growth changes are important in explaining the short run adjustments in the interest rate. Last, we find the estimate for the coefficient of expected consumption growth $\left(\rho_{2}\right)$ to be around $0.5-0.8$. This finding is compatible with earlier micro- and macroeconomic studies, which find the CRRA to be between 0.5 and 2.5 .

\section{Conclusion}

The effect of expected consumption growth on the interest rate is fundamental to the modern understanding of the consumer's allocation over time. However, this has been overlooked in empirical studies of the Fisher relation. We find that including a consumption growth term in the estimation of the Fisher equation helps explain the long run level of the interest rate and short run adjustments toward that level. The analysis also allows us to estimate the consumer's degree of relative risk aversion. Therefore, we conclude that the future studies of the Fisher relation would benefit from including expected consumption growth as an explanatory variable.

\section{References}

Caporale, G.M., Pittis, N., 2004. Estimator choice and Fisher's paradox: a Monte Carlo study. Econometric Reviews 23, 25-52.

Christopoulos, D.K., Leon-Ledesma, M.A., 2007. A long-run non-linear approach to the Fisher effect. Journal of Money, Credit, and Banking 39 (2-3), 543-559.

Crowder, W.J., Hoffman, D.L., 1996. The long-run relationship between nominal and inflation: the Fisher equation revisited. Journal of Money, Credit, and Banking 28, $102-118$.

Dotsey, M., Lantz, C., Scholl, B., 2003. The behavior of the real interest rate. Journal of Money, Credit, and Banking 35, 91-110.

Fisher, I., 1930. The Theory of Interest. MacMillan, New York.

Levi, M.D., Makin, J.H., 1978. Anticipated inflation and interest rates, further interpretation of findings on the Fisher equation. American Economic Review 68, 801-812.

Lucas, Robert E., Jr., 1978. Asset Prices in an Exchange Economy. Econometrica 46, 1429-1445.

Mehra, Y.P., 1993. The stability of the M2 demand function: evidence from an errorcorrection model. Journal of Money, Credit, and Banking 25, 455-460.

Ng, S., Perron, P., 1997. Estimation and inference in nearly unbalanced nearly cointegrated systems. Journal of Econometrics 79, 53-81.

Phillips, P., 2005. Econometric analysis of Fisher's equation. American Journal of Economics and Sociology 64 (1), 125-168.

Sarte, P.D.G., 1998. Fisher's equation and the inflation risk premium in a simple endowment economy. Federal Reserve Bank of Richmond Economic Quarterly 84, 53-72.

Sun, Y., Phillips, P.C.B., 2004. Understanding the Fisher equation. Journal of Applied Econometrics 19, 869-886.

VanderHoff, J., 1984. Evidence on the varying effect of expected inflation on interest rates. Review of Economics and Statistics 66, 477-481.

Westerlund, J., 2008. Panel cointegration tests of the Fisher effect. Journal of Applied Econometrics 23 (2), 193-233.

Weil, P., 1989. The equity premium puzzle and the risk-free rate puzzle. Journal of Monetary Economics 24 (2), 401-421. 